\title{
A Comparative Study between Learning Organizational Framework and UAE Government Initiatives
}

\author{
Srinivas Nowduri Ph.D. \\ College of Business Administration, American University in the Emirates, \\ International Academic City, Block 06, P.O.Box 503000, Dubai
}

\begin{abstract}
This research work compares the learning organizational framework with that of UAE government proposed initiatives towards its academic institutions from three different perspectives viz., 1. Four pillars of modern organizations 2 . Different layers of fostering a learning culture 3 . The life cycle of a high-performance learning organizations. A comparative study is made between learning organizations initiates and UAE proposed initiatives. Finally concluded with few influencing factors of UAE economy from academy perspective.
\end{abstract}

\section{INTRODUCTION}

Modern businesses in this technology era are forced to be more susceptible for changing technologies, and business processes; to remain competitive. At the same time people (employees) needs to be well equipped with their knowledge skills and decision-making capabilities; always, at all levels. It is thus challenging task for management to facilitate such a work environment, for better productivity and quality. By default, any organization is a conglomeration of people with several attitudes and psychologies; yet needs to work towards a single goal.

Thus, to make a business organization to be more successful, its high priority task should be to create and maintain a positive attitude, both in terms of services/products it delivers as well as workforce. Though it looks easy but very not that easy when it comes its implementation. Here attitude is referred to both management and employees. This task demands so called organizational knowledge creation. Organizational knowledge creation is the capability of members of an organization have developed to draw distinctions in the process of carrying out their work, in specific concreate contexts, by enacting sets of generalizations whose applications depends on historically evolved collective understanding [5][3].

For several centuries, scientists, philosophers and intelligent people have been concerned about creating, acquiring, and communicating knowledge and improving the re-utilization of knowledge; known to be todays knowledge management (KM). This KM field is solely based one premise that, just as human beings are unable to dear on the full potential of their brains, organizations are generally not able to fully utilize the knowledge that they possess. Recent research from countries such as the United Arab Emirates (UAE) and Qatar have highlighted significant advances in knowledge production [1]. It is generally believed that if an organization can increase its effective knowledge utilization by only a small percentage, a great benefit will result. Several researchers also recommended developing a research culture and improving the incentives to attract high quality researchers and talented workers [1][5][2]. Changing attitudes by changing behavior, especially in youth around the world, start contributing to the knowledge economy (KE). In the past UAE cabinet declared its 2021 vision of making the UAE among the best countries in the world through building a diversified knowledge economy. According to the latest research, the existing infrastructure on most UAE 
agencies, ranging from computing power, communication and technological readiness seem to be adequate [2]. In this modern digital era, the rapid changing technology trends are slowly start shaping the market trends. In organizations, how we can learn collectively, how organizations manage what they know, what are the ways of improving the performance by building organizational memory, are still few such open-ended questions. These research topics like $\mathrm{KM}$ and $\mathrm{KE}$ is beyond the scope of this current work.

In this modern digital era, the KM across organizations, specific to certain areas; leads to KE across the specific nations; leads to learning organization (LO), as shown in Figure 02 below:

Figure 02: Learning Organizations (LOs)
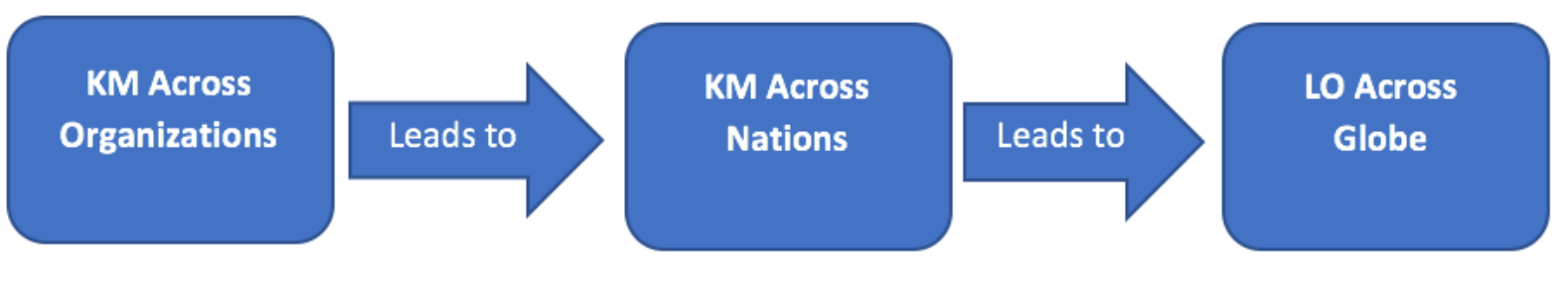

The idea behind LO has been a business process to change, like a clear 'plan' to an organization that intended implementation of continuous learning. At the same time, the organizational learning (OL), is the 'action' to be implemented. OL stress towards implementing change through an organization at front end; having the process and strategies at back end. This work more focus towards framework of LO towards its implementation within UAE's academic world. At a conceptual stage, according to Senge [1][2], the five influencing dimensions of LO include shown in the Figure 03.

Figure 03: The Different Parts of LO

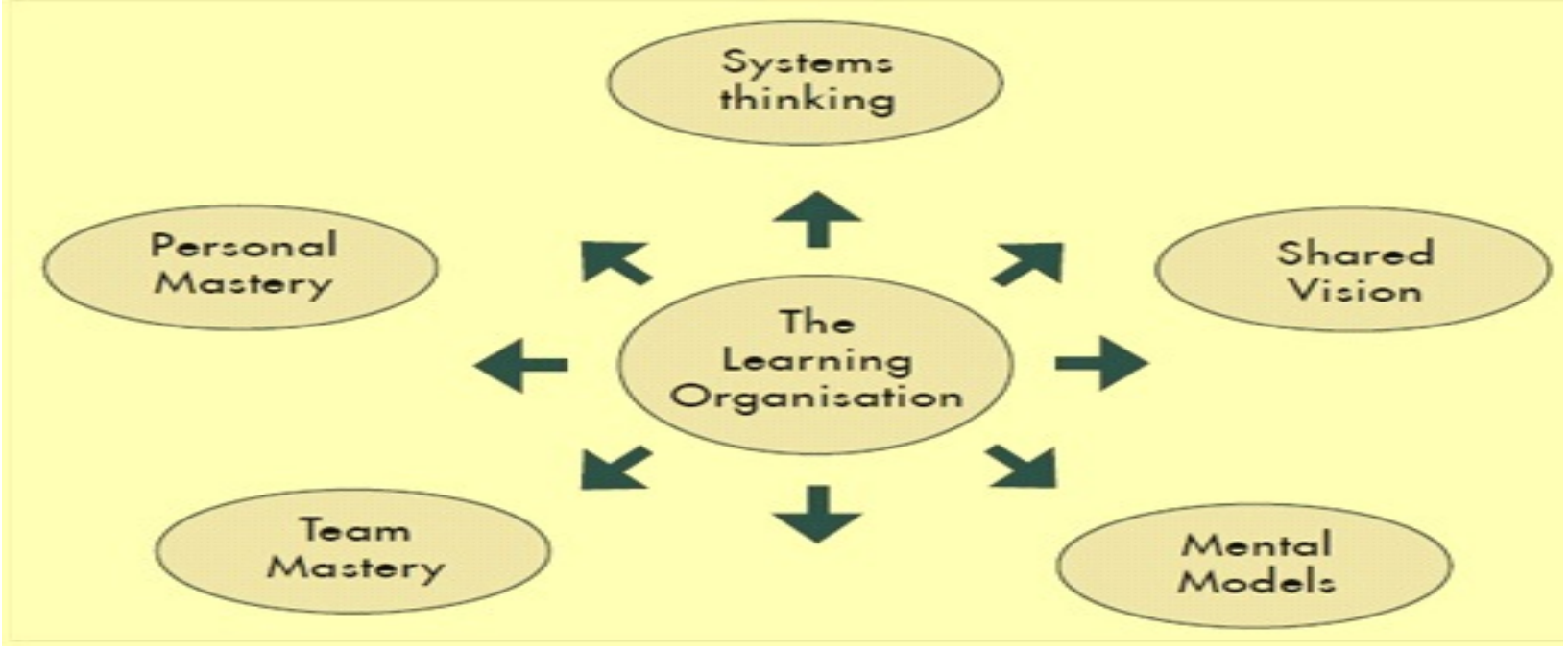

A. Systems thinking: The notion of treating the organization as a complex system composed of smaller (often complex) systems. This requires an understanding of the whole, as well as the components, not unlike the way a doctor should understand the human body. Some of the key elements here are recognizing the complexity of the organization and having a long-term focus. Senge advocates the use of system maps that show how systems connect

B. Personal mastery: Senge describes this as a process where an individual strives to enhance his vision and focus his energy, and to be in a constant state of learning. 
C. Mental models: "Deeply ingrained assumptions, generalizations, or even pictures and images that influence how we understand the world and how we take action" (Senge 1990). These must be recognized and challenged to allow for new ideas and changes.

D. Building shared vision: Shared vision is a powerful motivator. A leader's vision does not necessarily become shared by those below him. The key here is to pass on a picture of the future. To influence using dialogue, commitment, and enthusiasm, rather than to try to dictate. Storytelling is one possible tool that can be used here.

E. Team learning: The state where team members think together to achieve common goals. It builds on shared vision, adding the element of collaboration.

There are many strategical and philosophical view about LO, such as it helps organizations to remain: competitive, dynamic and stay with current technologies. In this technological era, LO idea is increasingly become relevant due to increasing complexity and uncertainty of organizational work environment; coupled with management strategies and customer demands. This has always opened a scope for fostering a 'learning culture' within the umbrella of LO.

There are many ways of fostering a learning culture across the organization; is start gaining the importance. This research focus more on comparative study between LO and the UAE government policies and governance. Though all cutting-edge technologies ultimately bringing a face-lift to the existing business organizations, are under the control of various information systems (ISs). Thus, business organizations start facilitating 'learning' environment to their employees, in improving their skills, as part of the management process.

There is no unique definition for LO, broadly speaking it is a virtual company or a firm that facilitates the 'learning' of its members and continuously transforms itself. Thus, employees learning is becoming the initial step for organizations' transformation. LO can also be visualized as learning environment, in tune with organizational goals, vision and mission. It is basically aimed at making people (employees) to be more creative, learning and more adoptable to the changing technologies and business needs.

Here one should remember, the organizational learning (OL) is different from that of LO; as OL is being complimentary to KM. In this fast-growing technological era, most modern businesses are intertwined and inter dependent on ISs giving a wide scope for their employees towards 'learning'. Broadly speaking these IS are two types viz., real systems and conceptual systems, with a premise that all real systems are recognized systems, with more emphasis towards 'programming techniques'; and all conceptual systems are just 'abstracted systems' as shown in Figure 04 below: 
Figure 04: A broad category of information systems for real life applications
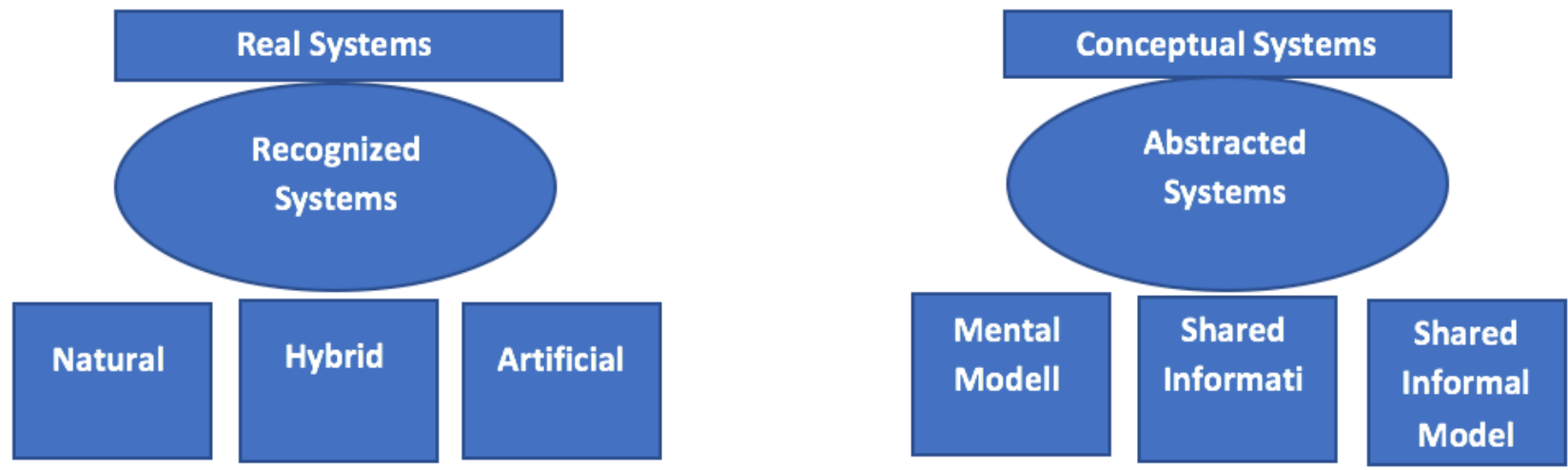

Most of the times, the idea behind "learning" in any business firm, is always come up with a map between "independence" and "inter-dependence" ISs; such as set of \{Natural, Mental \& Shared models\}, to the set of business activities such as \{Group coordination, Networked organizational \& Global systems\}. The higher level of employees' amount of 'knowledge' in above mapping, both in its 'premise' as well as 'conclusion'; leads to a higher LO concept known to be high performance learning organizations (HPLO).

\section{FOUR PILLARS OF MODERN BUSINESS ORGANIZATIONS}

Over the few decades, the rapid growth in technology and ISs have mold business organizations in several directions; making competitive. At the same time the organizational management start focusing on technology awareness campaign and its familiarity among its employees, to become king-player at market performance. At this junction, organizations start establishing four business pillars, for withstanding the market competitive pressure as well as meeting their corporate mission and vision. The four pillars are precisely the corporate strategic management issues, acceptable universally as defined below:

A. Employee development systems

B. Business process improvements

C. Technological link to business process methodologies

D. Employees' mindset

In general, a firm's capability is making the employees to respond effectively to change and support organizational performance; ultimately lead to organizational high-performance learning. Thus, the logical thread bridging LO and HPLO is the employees' mind set towards technology and its adaptation in all firm's business processes and strategies. This makes the following two things clear:

1. A clarity between continuous development of LO in above four different issues and

2. To have a makeshift in technological advancement to compete in the volatile markets.

Before we go further in this direction, let us have a look at the literature on LO, from its inception to the modern era, via transformational changes. In a fast spinning digital era, learning is become a vital component in all aspects of business as well as management processes, techniques and strategies.

\section{DIFFERENT WAYS OF FOSTERING A “LEARNING CULTURE”}

Foster a learning is the key to modern organizational success in several ways; in fact, it is one of the best ways of creating a LO by making sure everyone has time to reflect about each other's learning experience [6]. This is a starting point to get organizations heading in the right learning direction. This is precisely the starting point for a noble 'change process' both in 
employees' mindset as well as across the firm's business processes. From an external perspective every business organization is a series of layers, as shown below:

\section{Layer 01: People, Processes and Productivity (3Ps).}

People: An employee is an important asst for an organization, is always a mix of three different employee items: Cultures, Education and Habits. The management should be able to fine tune these items carefully, to sustain in the market. Sometimes the clear objectives and company objectives are immediately digestible for employees, takes some time.

Processes: These are more of dynamic by nature but need to be understood by every employee; as processes move the company towards better productivity and quality. Make sure that the organizational informal and formal processes, coupled with systems should not become barriers to employee's positive culture learning atmosphere.

Productivity: This is obviously the measure of the efficiency of a business firm, in converting inputs into useful outputs. This is invariably interlinked and intertwined with above two factors, with those people who are familiar with good process implementation; which occurs through proper learning culture.

\section{Layer 02: Engineer the Employees' Empowerment (3Es)}

In the digital era, employees' empowerment become essential part of the business process, as each department function is invariably interlinked with certain information systems (IS) and databases (DB). From the perspective of data security and data privacy, every organization start focus more towards engineering employees' empowerment opportunities to grow and develop; through it should not be a forced march. As a result, the management rule set, vision and mission, need to be based on employee' suggestions and comments.

Please be aware that all the learning culture assessments conducted within the organization, should not reveal those anti-learning elements among the employees.

\section{Layer 03: Develop, Derive and Drive (3Ds)}

Every business firm should initially concentrate on developing their own business in-house process. Sometimes one derive processes from the gained insight from competitive firms; in order to drive in competitive markets. The intrinsic driving force behind all these situations, is learning, at individual employee/team, as well as different management levels. Thus, the driving force behind each organizational process (weather it is developed or derived) is clearly a part of the organizational learning process.

Thus, the growth of LO is highly limited to above three specified layers of the organization. On the other hand, the concept of learning and its environment vary among different generations. For example, the current smart generation learning techniques are quite different than the earlier; both in terms of working as well as production hours. This have impact on its several entailed activities such as productivity, quality and accuracy. Thereby the modern organizations are governed by the purpose and powered by teamed capable people who use learning to achieve extradentary results for all stakeholders such as customers, employees, owners, suppliers and the communities within which the organization operated; constitutes high performing learning organizations (HPLO).

\section{HIGH PERFORMANCE LEARNING ORGANIZATIONS}

For any business firm, the 'techniques', 'strategies' and the 'methods' are all proved to be dynamic by default; with the understanding of incoming 'data' as secured and static. In this 
sense, 'learning' has been a prominent issue and useful tool for building HPLO. Added to this, in view of new generation of employees, with their mobiles in hand all the time, with high expectation that they get information and learning at their own time and from any location; measuring their performance become more challenging [6]. This force the basic structure of LO needs to re-structure and modify to qualify to be a HPLO. Here the idea behind learning is more towards life-long learning and iterative by as shown in Figure 05 below

\section{Figure 05: The life cycle of a HPLO}

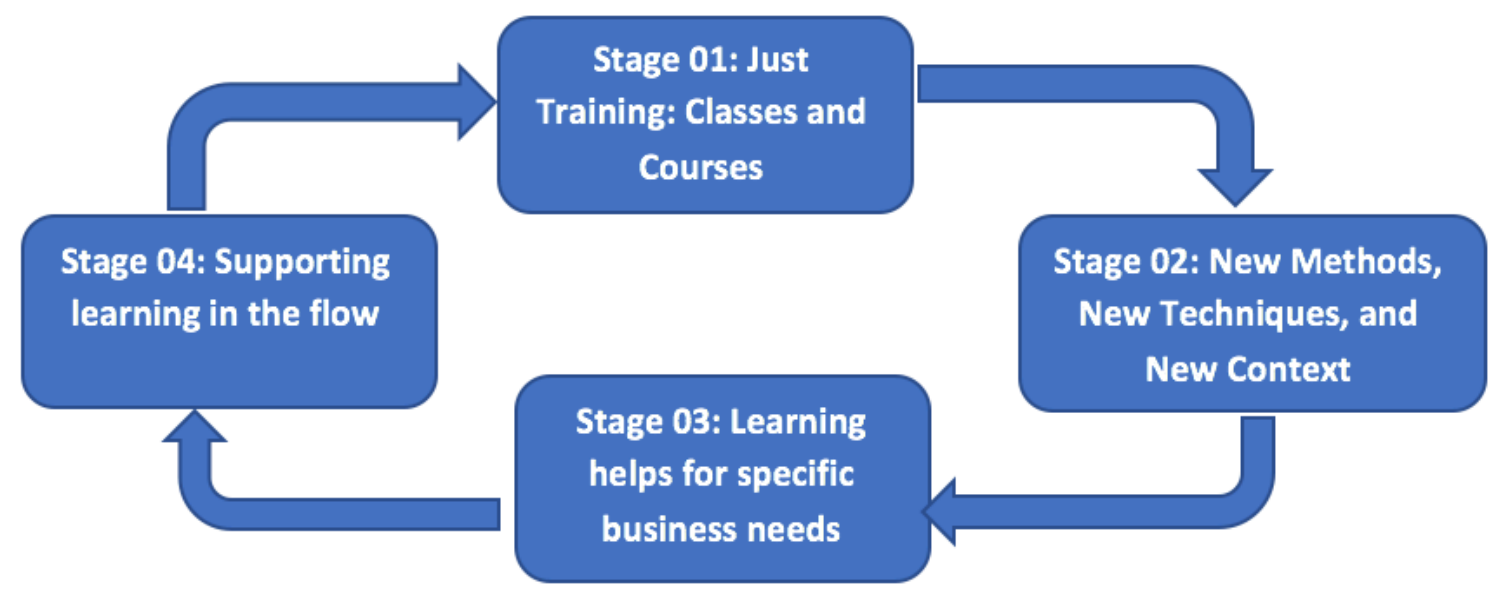

The above four stages of learning are by default cyclic since, organizational learning should be life-long learning. Conceptually HPLO is slightly different and superior from an ordinary LO, in terms culture of learning. Culture of corporate learning is uniform in which employees at all levels of an organization continuously seek, share and apply new knowledge and skills to improve their own performance as well as that of the firm. In this sense, a HPLO is characterized from two broad agendas viz.,

(a) Different ways of support workforce learning and

(b) Plotting graph between the employee's performance against their maturity level.

With the premise of 'learning' leads to organizational 'growth', HPLOs demark themselves; as powerful and useful for modern society. It emphasizes that leaders are the integral part of the learning cultures, with employees being the main ingredients. Their strategies and business views are more adoptable for the new generation. Further these are a level above to the Senge [xyz] suggested LO, but close to the Peter [1][2] suggested five competitive forces.

The HPLO stay as intersection among the 'right people', "right environment' and 'right processes'; thereby they targeted towards following four basic strategies as stated below [6]:

Designated for Growth: HPLO put their time and energy in two key processing areas (KPA): 1. Improving the performance of employees in their current role through in-the-movement learning and 2. They offer longer-term development paths. Learning should be from employee's perspective and focus on (a) simplifying an employee's work life, (b) anticipating employees needs, (c) eliminating the barriers to learning and (d) delivering experiences that are relevant, current and in the moment.

Support Engineered Exploration: Through process and decision-making clarity, organizations encourage greater risk-taking and exploration among employees. Thereby the conditions that allow an individual to control their destiny and influence their future. 
Offer Guided Adaptation: Invest time in making learning happen faster for the individual and for the organization so that they leveraging that learning every day to accelerate performance, move faster and adapt quicker.

Engage in Accelerated Evolution: Organizations evolve as a result of their learning, rapidly adjusting their mental frameworks and mindsets. Encourage learning on the fly, help improving the quality conversations between a supervisor and employees

Having said the views of HPLO, let us now look at applicable economies across the world. The basic strength of any nation's corporate/industrial growth is based on its government vison and mission.

\section{THE BASIC VISION AND MISSION OF UAE GOVERNMENT}

A decade back, the UAE's government launched its vision for 2021, which sets the key themes for the social and economic development of UAE and calls for a face-shift to a diversifies and knowledge-based economy. This program will be supervised by The Ministry of Cabinet Affairs. This program is multidimensional and aims to provide the Emirati nationals with the highest possible standards of welfare. The needs and aspirations of Emiratis "are at the core of the development process as set by the UAE Vision 2021", Sheikh Mohammed said. On the day following the launch of this program, the Crown Prince tweeted in English: "Today we set our goals for the govt. of Dubai in 2021, as we march confidently towards the future \& new horizons", adding "In a first of its kind initiative, the government aims to compete with the private sector in terms of the caliber of service it provides. His Highness Sheikh Mohammed bin Zayed Al Nahyan." [7]. The main agenda in it include:

- World class health care

- First-rate education system

- Sustainability environment and infrastructure

- Public safety and fair judiciary

Added to this supports four principles that guide the march of the UAE country viz., 1. Learning skills 2. Mathematics, 3. Science and 4. Arts. This also coupled with proper reflection and resolution towards four areas viz., Responsibility, Density, Knowledge and Prosperity.

\section{COMPARATIVE DIRECTIONS OF LO AND UAE GOVERNMENT VISION}

About a decades back, in 2010, the UAE Government launched the UAE vision 2021, which charts the next stage of UAE journey until the year 2021. The vision aims to position the UAE among the best countries in the world by the Golden Jubilee of the federation in 2021. In 2014, Sheikh Mohammed launched a seven-year National Agenda in order to guide efforts towards Vision 2021. The Agenda was the result of a series of workshops attended by over 300 officials from 90 federal and local government entities, participants from civil society organizations and the private sector and experts from academia and research institutions [7]. The agenda specifies a wide-ranging work program centered around 6 national priorities, as the key focus of government strategy in the coming years, and 52 National Key Performance Indicators (NKPIs) in the sectors of education, healthcare, economy, police and security, justice, society, housing, infrastructure and government services. The six UAE national priorities are:

1. cohesive society and preserved identity

2. safe public and fair judiciary

3. competitive knowledge economy

4. first-rate education system

5. world-class healthcare

6. sustainable environment and infrastructure 
The above proposed National Key Performance Indicators (NKPIs) are long-term, measure performance outcomes in each of the national priorities and generally compare the UAE against global benchmarks. The national indicators are periodically monitored by Government leadership to ensure their targets are achieved by 2021.

In 2010, H.H. Sheikh Mohammed bin Rashid Al Maktoum, Vice-President and Prime Minister of the UAE and Ruler of Dubai, launched the UAE Vision 2021, which aims to make the UAE one of the best countries in the world by the Golden Jubilee of the Union. Providing firstrate education system is a pillar of the National Agenda in line with Vision 2021. One of the targets of National Agenda is that UAE students must be best in the world in reading, mathematics, science and have a strong knowledge of the Arabic language. The United Arab Emirates Vision 2021 has education as its foundation, both explicitly and implicitly. Vision 2021 includes aspirations for citizenship, a spirit of entrepreneurship, enhanced educational attainment, and a knowledge-based economy driven by innovation, research, science and technology.

Currently the UAE government has already established its vision for 2021 and beyond, basically to strengthen its economy. The above proposed agenda was prepared by a committee of expert from different ministries and wings of the UAE government. Figure 08 below, clearly shows, this proposed agenda is in comparison between Senge [1][2] prosed steps for a LO. Further it also through some light how different ways UAE is heading towards HPLO.

In a span of two decades, the number of UAE academic institutions growth is a clear indication about its economic growth and youth participation in educational careers. Each year the number of academic intuitions joining UAE's academic community is signaling the light towards LO and beyond LO. Though UAE government propose its vision and mission long back, in the form of five different strategies, are now in close comparison with that of Senge [1][2] proposed five dimensions of LO. At the same time, their implementation is in the hands of UAE youth, pursuing their learning.

\section{Figure 08: Comparative study between LO and UAE Government Initiative}

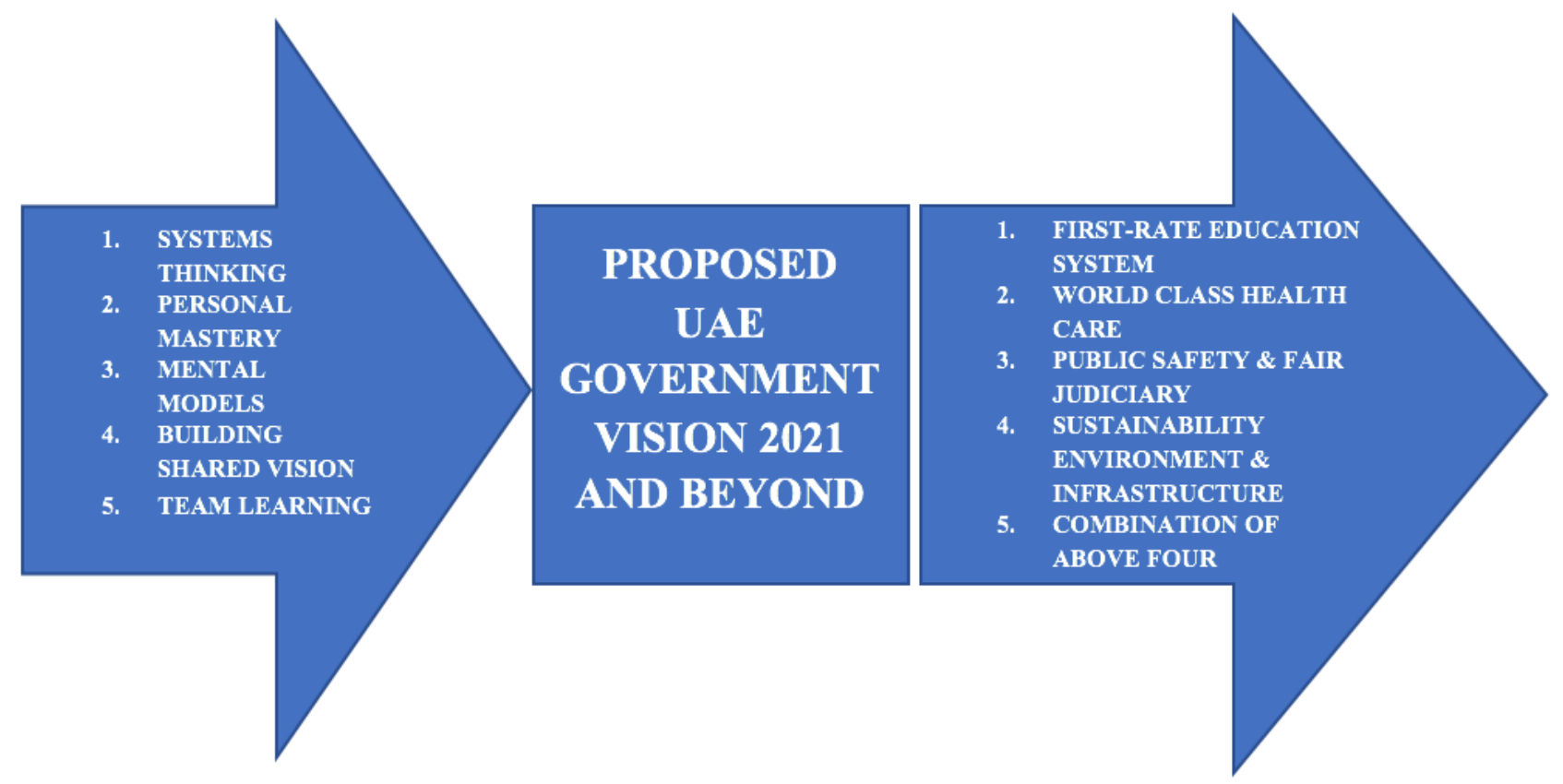


Logically speaking the five dimensions of Senge's LO model is in fact justifiable and comparable with those of five UAE proposed five visionary plans for 2021 and beyond, as described below:

1. The Systems thinking, should be commenced with establishing a first-rated education system

2. The personal mastery is always well connected with health care system; especially in youth.

3. The mental models need to be tied up with intuitional legal system viz., public safety and fair judiciary

4. The building shared vison always comes up with intuitional environment and suitability issues.

5. Finally, the team learning is much more than group thinking. It focusses on the transmission of both tacit and explicit knowledge, through groups as well as creation of an environment in which focused creativity can flourish. Thus, it is a linear combination of all the four components detailed above.

With a clear learning plan and learning operations, UAE government is start dispersing the right leaders with right behaviors and right resources. This is a strategic measure by the AUE government with its background 'learning plan' and 'learning operations', propose building a 'learning culture' across all its academic institution as shown in Figure 09 below:

Figure 09: Building a 'learning culture' in UAE academic institutions

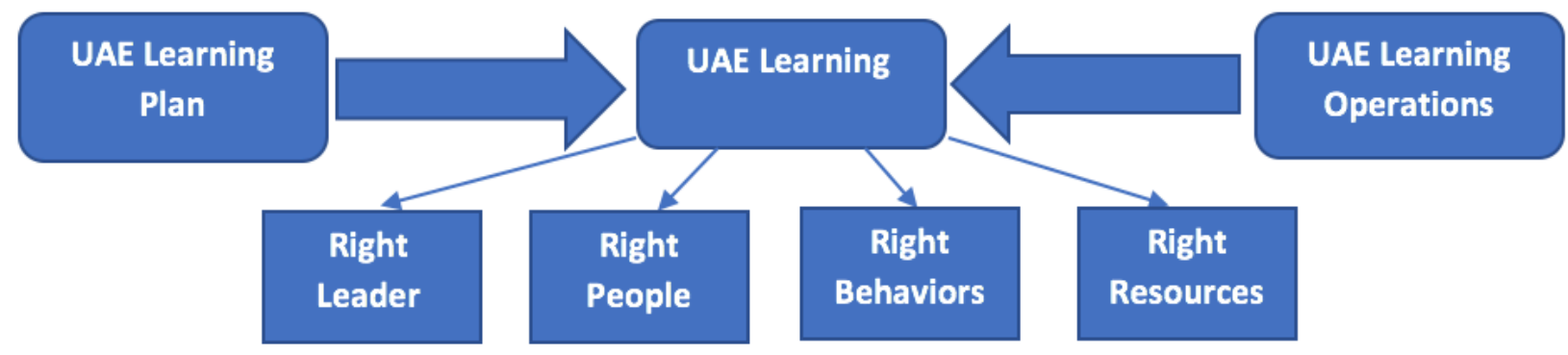

\section{INFLUENCE FACTORS OF UAE'S ECONOMY: AN ACADEMIC PERSPECTIVE}

The five proposed agenda of LO are basically designed for the basic purpose of creating selforganization, with an idea of groups can come close to explore through communication and other forms of feedback, coupled with other forms and variety degrees of 'inter-dependencies'. The influence of these five factors are indirectly or directly could impact the UAE economy; which is beyond this research work. But the existing concerns such as youth balancing the WSC, growing per capita income, government move towards research intensive institutions is a clear indication that, the nation is moving towards HPLO.

1. An Overview of Learning Organizations (LOs): The basics of learning organizations (LOs), along with their promising strategies as applicable within UAE.

2. Balancing Work-Study Culture: The most modern AUE youth are opting for work-study culture from their socio, economic and cultural perspective.

3. Growing and Returning Human Capital: Here the more stress is more towards per capita income and expenditure, along with social norms and family bindings.

4. A Move Towards Research Intensive Institutions: The government vision is to establish the research-intensive institutions across UAE, such as solar energy research, banking sector network hub for middle east, etc.

5. Western influence and impact: The UAE government stress is measuring the impact of western influence and impact while addressing the local issues, coupled with UAE youth influencing attitudes towards education system. 
The success path of any influenced person always lies in his/her foot in creating and maintaining a positive attitude. If he/she is leader, then his/her attitude draws people to his/her side and encourage them to do their best work. Similarly, if he/she is an educator, then attitude draws his/her student population towards his/her topic of discussion. There are eight specific ways to improve young students' attitude:

- Always act with a purpose

- Stretch yourself past your limits every day

- The action without expecting results

- Use setbacks to improve your skills

- Seek out those share your positive attitude

- Don't take yourself to seriously

- Forgive the limitations of others

- Say 'thank you' more frequently

\section{CONCLUSIONS AND FUTURE POSSIBILITIES}

This research concludes that the UAE government proposals towards its economic development measure is very much comparable with that of LO initiatives proposed by Senge [1][2][5] few decades back. Second, it is concluded that there are three different layers for fostering a learning culture among the UAE youth. Third, future projection is given how the UAE can go for HPLO level, though its four different stage of a life cycle. Finally concluded with a learning culture framework in UAE academic institutions.

\section{References}

Parcero, O.J and Ryan J. C (2016), Becoming a knowledge economy: The case of Qatar, UAE and 17 benchmark countries, Journal od the Knowledge Economy, Vol. 1, No. 28, http://dx.doi.org/10.1007/s13132-016-0355-y

Hijazi, Saeed and Alfaki (2019), Role of Statistician in Building the UAE Knowledge Economy, Electronic Journal of Applied Statistical Analysis, Vol. 12, Issue 01, April 2019, 303-319

Sherif Kamel (2017), Education in the Middle East: Challenges and Opportunities, International Conference ICTO, Paris March 16-17, 2017

Ryan and Daly (2019), Barriers to Innovation and Knowledge Generation: The Challenges of Conducting Business and Social Research in an Emerging Country Context, Journal of Innovation and Knowledge, Vol. 04, 2019 Pp. 4754

Tsoukas and Vladimirou (2002), What is Organizational Knowledge? Journal of Management Studies, Vol. 38, Issue 7, 2002

Website: https://www.d2l.com/en-mea/corporate/blog/4-strategies-high-performing-learning-organizations/

Website:https://www.government.ae/en/about-the-uae/strategies-initiatives-and-awards/federal-governmentsstrategies-and-plans/national-agenda 